\title{
Microcomputed X-ray Tomographic Imaging and Image Processing for Microstructural Characterization of Explosives
}

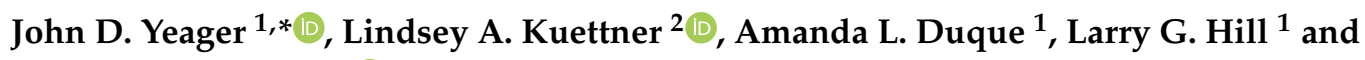 \\ Brian M. Patterson $2, *$ (D) \\ 1 High Explosives Science and Technology, Los Alamos National Laboratory, Los Alamos, NM 87545, USA; \\ aduque@lanl.gov (A.L.D.); lgh@lanl.gov (L.G.H.) \\ 2 Engineered Materials, Los Alamos National Laboratory, Los Alamos, NM 87545, USA; lkuettner@lanl.gov \\ * Correspondence: jyeager@lanl.gov (J.D.Y.); bpatterson@lanl.gov (B.M.P.); \\ Tel.: +1-505-665-0879 (J.D.Y.); +1-505-606-0831 (B.M.P.)
}

Received: 11 September 2020; Accepted: 5 October 2020; Published: 12 October 2020

\begin{abstract}
Microstructural characterization of composite high explosives (HEs) has become increasingly important over the last several decades in association with the development of high fidelity mesoscale modeling and an improved understanding of ignition and detonation processes. HE microstructure influences not only typical material properties (e.g., thermal, mechanical) but also reactive behavior (e.g., shock sensitivity, detonation wave shape). A detailed nondestructive 3D examination of the microstructure has generally been limited to custom-engineered samples or surrogates due to poor contrast between the composite constituents. Highly loaded ( $>90 \mathrm{wt} \%) \mathrm{HE}$ composites such as plastic-bonded explosives (PBX) are especially difficult. Here, we present efforts to improve measurement quality by using single and dual-energy microcomputed X-ray tomography and state-of-the-art image processing techniques to study a broad set of HE materials. Some materials, such as PBX 9502, exhibit suitable contrast and resolution for an automatic segmentation of the HE from the polymer binder and the voids. Other composite HEs had varying levels of success in segmentation. Post-processing techniques that used commercially available algorithms to improve the segmentation quality of PBX 9501 as well as zero-density defects such as cracks and voids could be easily segmented for all samples. Aspects of the materials that lend themselves well to this type of measurement are discussed.
\end{abstract}

Keywords: microstructure; explosives; microcomputed tomography; dual energy; segmentation; composites; polymer matrix composites

\section{Introduction}

A characterization of the microstructure of high explosives (HEs) is important for constructing accurate mesoscale simulations; understanding processing-structure-property relationships, which influence initiation and detonation behavior; and quantifying production parameters (i.e., lot-to-lot variations). The microstructure of $\mathrm{HE}$, and in particular grain size and size distribution, has been shown to affect shock sensitivity [1], detonation velocity [2], critical diameter [3], detonation front curvature [4], and corner turning [5]. Other relevant features of the microstructure include, but are not limited to, grain morphology [6], distribution of constituents [7], void size distribution [8], shape of void [9], and damage [10]. Further, multiple categories of explosives exist and have their own unique behavioral traits. Plastic-bonded explosives (PBX) are highly-loaded polymer matrix composites that can be formulated in a wet slurry process and pressed or formulated 
as cast-curable materials [11-13]. The polymers ("binders") can be inert and only serve to enhance stability and machinability, or they can be somewhat energetic themselves and contribute to the detonation energy [14]. Melt-castable explosives can be a single low melt temperature material (e.g., trinitrotoluene) or a mixture of explosives, where at least one component is melt-castable so it can serve as a binder (e.g., Composition B) while imparting high detonation energy [15]. Some explosives are simply used as a powder or pressed into a pellet without a binder ("neat") [16]. As is the case in many materials, quantifying all microstructural features with a single technique is difficult if not impossible; since most explosives are relatively fragile, not to mention hazardous, obtaining accurate measurements is especially challenging.

Historically, most of the microstructural characterization of HE has been done in 2D with optical microscopy or similar methods [17-19]. The data can then be used as a starting point for simulations either directly (e.g., digitizing 2D images) or indirectly (e.g., numerically generating microstructures that match the measured particle size and morphology) $[6,20,21]$. These approaches have advantages in terms of experimental and computational efficiency, but they also have limitations in their ability to quantify and accurately assess damage and other microstructural features across representative amounts of material. Probably the most commonly used 3D characterization technology at this scale is X-ray microcomputed tomography $(\mu \mathrm{CT})$, and several recent works have explored the feasibility of using $\mu \mathrm{CT}$ to comprehensively characterize explosives or explosive-like surrogates [22-25]. While $\mu \mathrm{CT}$ can be an expensive technique (i.e., in cost, data, and time), it is often worth the effort because it can quantitatively measure voids, particles, cracks, and other features, and it can also be used to track the changes of these features due to external insult [26-28]. For traditional materials, $\mu \mathrm{CT}$ is often used as input data to create 3D meshes of materials as a realistic starting point for mesoscale modeling. For an accurate mesh construction of heterogeneous materials, the various constituent phases must have sufficient $X$-ray contrast to enable segmentation.

Unfortunately, most explosive constituents have little X-ray contrast, mainly due to similar composition and density. These difficulties are exacerbated in cases where the material is close to theoretical maximum density, or when the composite explosive is very highly loaded ( $>90 \% \mathrm{HE}$ ). In short, measurement of "real" explosives with $\mu \mathrm{CT}$ has been generally limited to detecting voids or cracks $[25,29,30]$, and fully segmentable microstructures have only been obtained by using engineered or optimized samples $[23,24,31]$. An analysis of voids and cracks is still useful for safety and initiation modeling $[8,32,33]$, but full spatial information would greatly enhance these efforts while also enabling real microstructures (i.e., accurately described crystal and binder distribution) to be used for mesoscale simulations (e.g., [34]).

In order to obtain optimized images for typical (non-HE) samples, state-of-the-art instrumentation relies on a variety of techniques including automated ring artifact removal, multiple background collections to remove instrument drift, and automated filtering to reduce beam hardening artifacts. To optimize the sample contrast, instruments are also capable of fine-tuning the $\mathrm{X}$-ray energy through source energy selection, filter application, and dual-energy imaging to improve the contrast in similar atomic number samples. After the data are collected, modern software packages also invoke a plethora of imaging filters (i.e., median, unsharp, edge-preserving to name a few) that are used to smooth out noise and enhance edges. Finally, segmentation techniques have been developed that are as simple as choosing a grayscale range, to watershed, auto intensity correlation, and state-of-the-art texture-based machine learning. Determining the correct combination of all of these parameters is a difficult and time-consuming challenge, and this results in a final image quality that is much an art as it is a science [35].

Here, to evaluate the state-of-the-art in laboratory-based $\mu \mathrm{CT}$ for HEs, we imaged ten different HE materials at their typical density and composition. The chosen materials are of interest to a wide variety of modern explosive and weapons applications. This study resulted in a library of high-quality images for future modeling and morphological studies. Additionally, a variety of techniques were investigated, with varying success, in postacquisition image segmentation. The human brain is very 
well developed in defining the edge boundaries between crystals and the binder. However, $\mathrm{HE}$ and $\mathrm{HE}$ composite materials represent about as tough a materials science challenge in segmenting images as any material system. HE crystals have densities and atomic composition that are nearly identical to the modern binders used to hold them together. Initially, we discuss the most conducive PBX system for $\mu \mathrm{CT}$ imaging, then evaluate six PBX materials with various polymer binders, and finally we measure HEs with no polymer binder. A variety of image acquisition and post-processing techniques will be demonstrated, including optimized X-ray energy, dual energy imaging, filtering, and advanced segmentation approaches. While dual energy $X$-ray imaging is used in security applications to detect the presence or absence of explosives, to our knowledge, this is the first presentation of the use of dual-energy $\mu \mathrm{CT}$ to improve the contrast in the study of the microstructure within HE composite systems.

\section{Materials and Methods}

\subsection{Materials}

A full list of the ten HE materials studied here is given in Table 1. The materials variously contained the explosives cyclotetramethylene-tetranitramine (HMX), cyclotrimethylenetrinitramine (RDX), triamino-trinitrobenzene (TATB), and trinitrotoluene (TNT). Six of the materials were traditionally-manufactured PBX formulations, with the HE filler being around 95\% by weight and the remainder a polymer binder. Polymers included the block copolymer Estane, the fluropolymer Kel-F, the fluoropolymer Viton A, hydroxyl-terminated polybutadiene (HTPB), and nitrocellulose. The seventh PBX formulation, HMX-HTPB, was similar to a previously studied formulation that had been shown to be highly measurable with $\mu \mathrm{CT}$. Two formulations were melt-castable, where TNT was used as the matrix that contains other HE crystals. The tenth material was TATB without a binder. These materials were chosen to span a variety of HE formulation conditions, processing methods, particle size distributions, and binder materials.

Table 1. High explosive materials studied with $\mu \mathrm{CT}$.

\begin{tabular}{|c|c|c|}
\hline Sample & Mass Composition (wt \%) & Processing Method \\
\hline HMX-HТРВ & $\begin{array}{l}80 \% \mathrm{HMX}^{1} \\
20 \% \mathrm{HTPB}^{2}\end{array}$ & Cast cured as a block, then cut to shape \\
\hline PBX 9501 & $\begin{array}{c}95 \% \text { HMX } \\
\text { 5\% Plasticized Estane } 5703\end{array}$ & Slurry formulated to form molding prills, then pressed \\
\hline PBX 9502 & $\begin{array}{c}95 \% \text { TATB }^{3} \\
5 \% \text { Kel-F }\end{array}$ & Slurry formulated to form molding prills, then pressed \\
\hline PBX 9404 & $\begin{array}{c}94 \% \text { HMX } \\
6 \% \text { Plasticized Nitrocellulose }\end{array}$ & Slurry formulated to form molding prills, then pressed \\
\hline LX-14 & $\begin{array}{c}\text { 95.5\% HMX } \\
4.5 \% \text { Estane } 5703\end{array}$ & Slurry formulated to form molding prills, then pressed \\
\hline PBXN-5 & $\begin{array}{r}95 \% \text { HMX } \\
5 \% \text { Viton A }\end{array}$ & Slurry formulated to form molding prills, then pressed \\
\hline PBXW-14 & $\begin{array}{c}50 \% \text { HMX } \\
45 \% \text { TATB } 5 \% \text { Viton A }\end{array}$ & Slurry formulated to form molding prills, then pressed \\
\hline Composition B & $\begin{array}{l}60 \% \mathrm{RDX}^{4} \\
40 \% \mathrm{TNT}^{5}\end{array}$ & Melt cast, then pressed \\
\hline Octol & $\begin{array}{l}75 \% \text { HMX } \\
25 \% \mathrm{TNT}\end{array}$ & Melt cast, then pressed \\
\hline TATB & $100 \%$ TATB & Pressed \\
\hline
\end{tabular}

1 HMX: cyclotetramethylene-tetranitramine, ${ }^{2}$ HTPB: hydroxyl-terminated polybutadiene, 3 TATB: triamino-trinitrobenzene, ${ }^{4}$ RDX: cyclotrimethylenetrinitramine, ${ }^{5}$ TNT: trinitrotoluene.

Measurement specimens were primarily used as-supplied from the appropriate production agencies and were made by compacting raw materials into $3.2 \mathrm{~mm}$ diameter $\times 6.4 \mathrm{~mm}$ tall right circular cylinders. Compaction into solid samples was achieved by die-pressing at ambient temperatures to an 
approximate pressure of $41.5 \mathrm{kPa}$ in a hardened steel die. Composition B and Octol are traditionally melt-cast to shape, but for better comparison at this small sample size, premixed materials (flakes) were pressed identically to the PBX samples. Final part densities for all pressed samples were within the specification for their typical application. The HMX-HTPB sample required a curing process for the binder to become stable, and so it was cast as a large block instead of pressed; $3 \mathrm{~mm}$ diameter $\times 3 \mathrm{~mm}$ tall cylindrical samples were bored out of the block for measurement.

It should be noted that these sample sizes were optimized for the $\mu \mathrm{CT}$ measurements, and while they are representative of processes used to make full-scale HE charges, this probably introduced higher damage to the material than would be expected at larger scales. The unintended benefit of this was that microstructural defects such as cracks and voids would be more ubiquitous than in traditionally manufactured material, highlighting the utility of the $\mu \mathrm{CT}$ technique for characterizing such defects. Some care should be taken before comparing the results found here for any given material to "bulk" or typical large scale material microstructure.

\subsection{Computed Tomography}

Three Micro X-ray CT images $(\mu \mathrm{CT})$ were collected of many of the samples using an Xradia Versa 520 MicroXCT (Carl Zeiss X-ray Microscopy Inc., Pleasanton, CA, USA). A high resolution image $(\approx 0.8$ micrometers voxel size) was collected of each sample, and two lower resolution images were collected on many of the samples to explore the possibility of using dual-energy imaging to improve imaging contrast. The system uses a microfocus $\mathrm{X}$-ray source with a transmission tungsten anode. A scintillator converts the $\mathrm{X}$-ray photons to visible light photons and is mounted on the front of the objective, which then transmits the optical photons to the $1 \mathrm{k} \times 1 \mathrm{k}$ piezoelectrically cooled detector. The $20 \times$ objective was used, except as noted, with no source filter; the sample was rotated $360^{\circ}$ while imaging, and a binning of 2 was used on the detector. The high-resolution image of each sample was collected, and their imaging conditions are outlined in Table 2. Each used a peak potential of $50 \mathrm{kV}$ and a total of $4 \mathrm{~W}$ power. The images were reconstructed using the TXMReconstructor (Carl Zeiss X-ray Microscopy Inc., Pleasanton, CA, USA) and rendered and quantified using Avizo Inspect 2020.1 (Thermo Fisher Scientific, Hillsboro, OR, USA). The images were smoothed with an edge-preserving filter and segmented based upon the grayscale values; the crystals, binder, and voids were separated and quantified.

Table 2. Imaging conditions used for the high resolution images of the pressed pellets.

\begin{tabular}{ccccc}
\hline Sample & Images & Time $(\mathbf{s})$ & Pixel Size $(\mu \mathrm{m})$ & Dual Energy? \\
\hline HMX-HTPB & 4501 & 30 & 0.82 & \\
PBX 9501 & 4501 & 20 & 0.76 & $\mathrm{X}$ \\
PBX 9502 & 4501 & 25 & 0.76 & $\mathrm{X}$ \\
PBX 9404 & 4501 & 20 & 0.76 & $\mathrm{X}$ \\
LX-14 & 4501 & 20 & 0.76 & $\mathrm{X}$ \\
PBXN-5 & 4501 & 25 & 0.76 & $\mathrm{X}$ \\
PBXW-14 & 3201 & 13 & 0.84 & \\
Composition B & 4501 & 25 & 0.76 & $\mathrm{X}$ \\
Octol & 2401 & 15 & 0.89 & \\
TATB & 4501 & 25 & 0.76 & \\
\hline
\end{tabular}

\section{Results}

\subsection{Plastic-Bonded Explosives}

Figure 1 shows a typical $\mu \mathrm{CT}$ for the HMX-HTPB sample. The lighter material is the HMX, while the black constituent is void, and the intermediate grayscale material is the binder. This contrast scheme is consistent for all the CT images shown here, as the grayscale value is lighter as density increases. This particular HMX-HTPB formulation was manufactured with Class V HMX only, 
meaning that effectively all HMX particles were smaller than $45 \mu \mathrm{m}$ in diameter as measured with sieve cuts. The resulting microstructure is an approximately monomodal distribution of HMX, and the binder appears to be reasonably well intermixed but definitely has some regions of higher concentration. As mentioned earlier, single energy $\mu \mathrm{CT}$ measurements of this class of material have been proven sufficient for material segmentation to create meshes for modeling, and it represents a "gold standard" for PBX microstructure characterization [23].

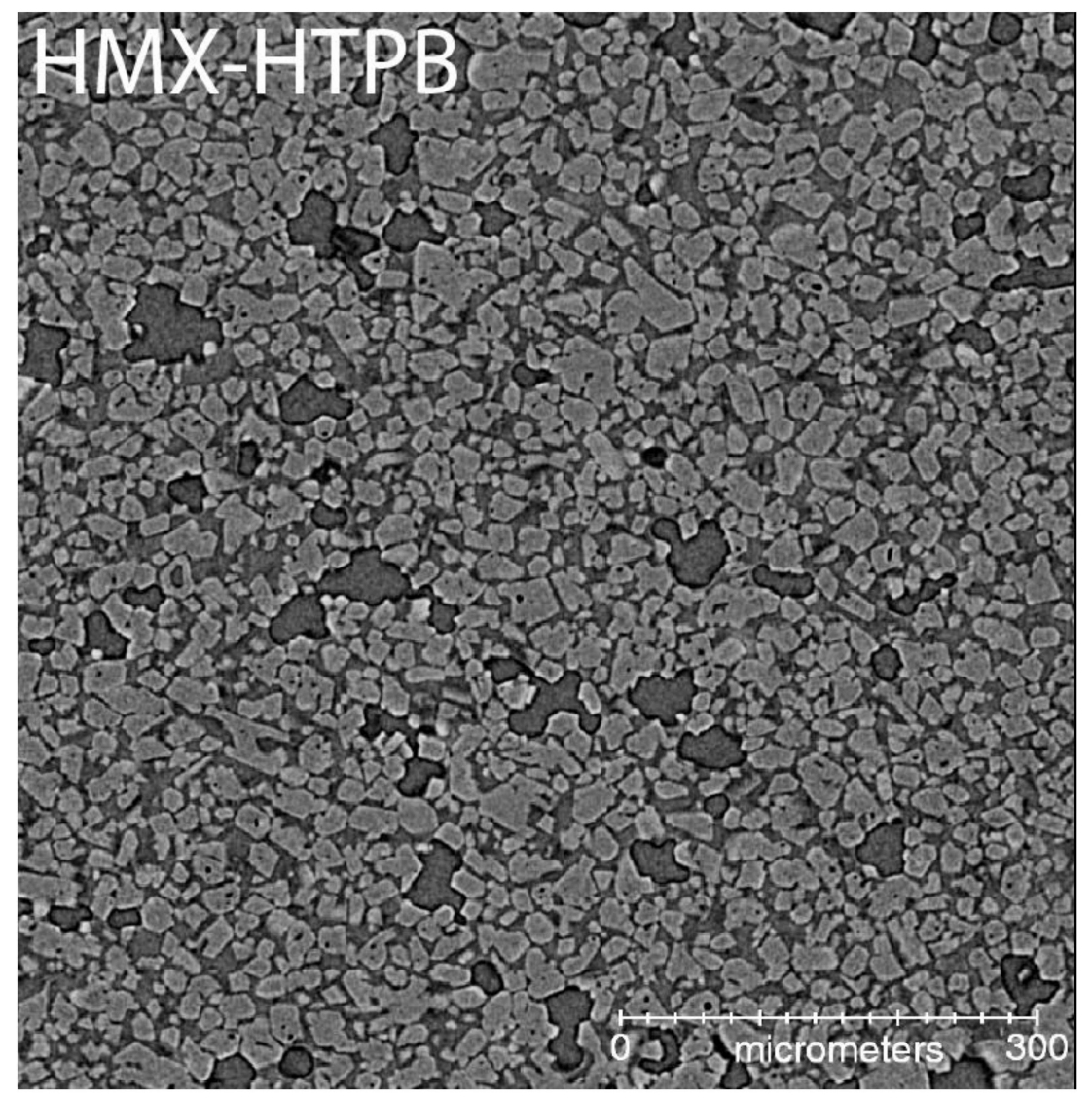

Figure 1. HMX-HTPB formulation imaged with high resolution X-ray microcomputed tomography $(\mu \mathrm{CT})$. The crystals are the light gray, the binder is a medium gray, and the voids are the darkest gray. Some phase contrast (light-dark halo) is seen around the voids. This is minimized by reducing the distance from the sample to the detector scintillator.

Figure 2 shows the results of the segmentation of the HMX-HTPB system. The densities of the $\operatorname{HMX}\left(1.9 \mathrm{~g} / \mathrm{cm}^{3}\right)$ and the HTPB $\left(0.9 \mathrm{~g} / \mathrm{cm}^{3}\right)$ are sufficiently different that this system can be segmented for voids, crystals, and binder. Upon data collection and importing into Avizo, an "edge-preserving smoothing" filter was used with values of (stop $=1000$, step $=100$, contrast $=100,000$, and sigma $=0$ ). For this filter, a range of decades $\left(10^{3}\right.$ to $\left.10^{6}\right)$ of "contrast" were explored and optimized, while the other values were held constant. Then, a combination of "magic wand" and simple grayscale threshold was used to create the segmented image. 
a)

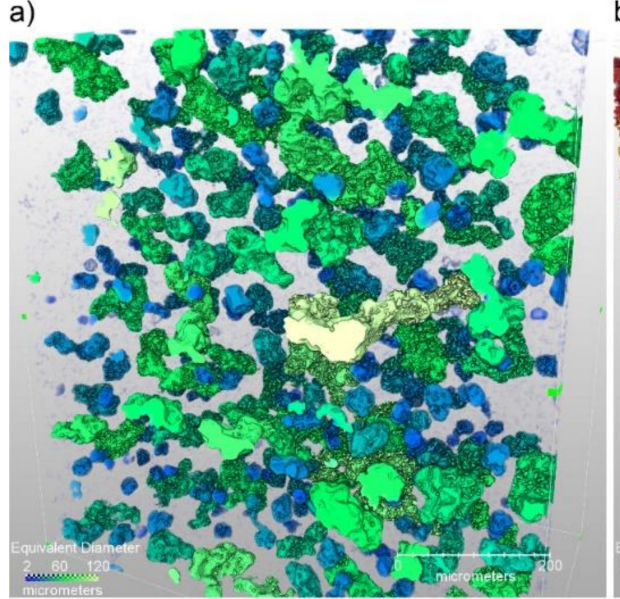

b)

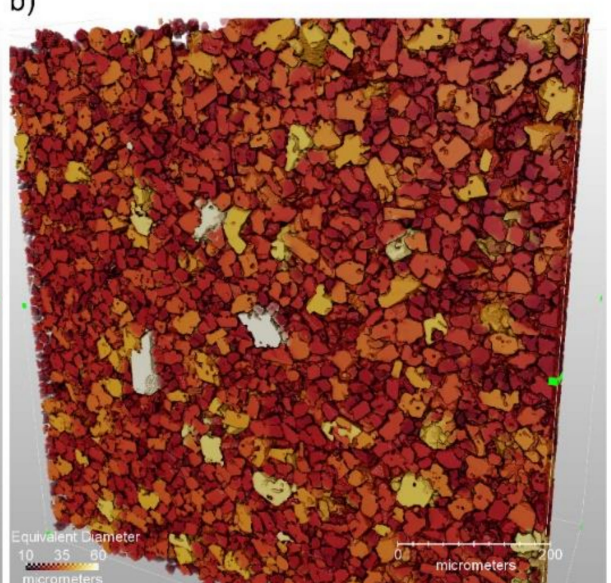

c)

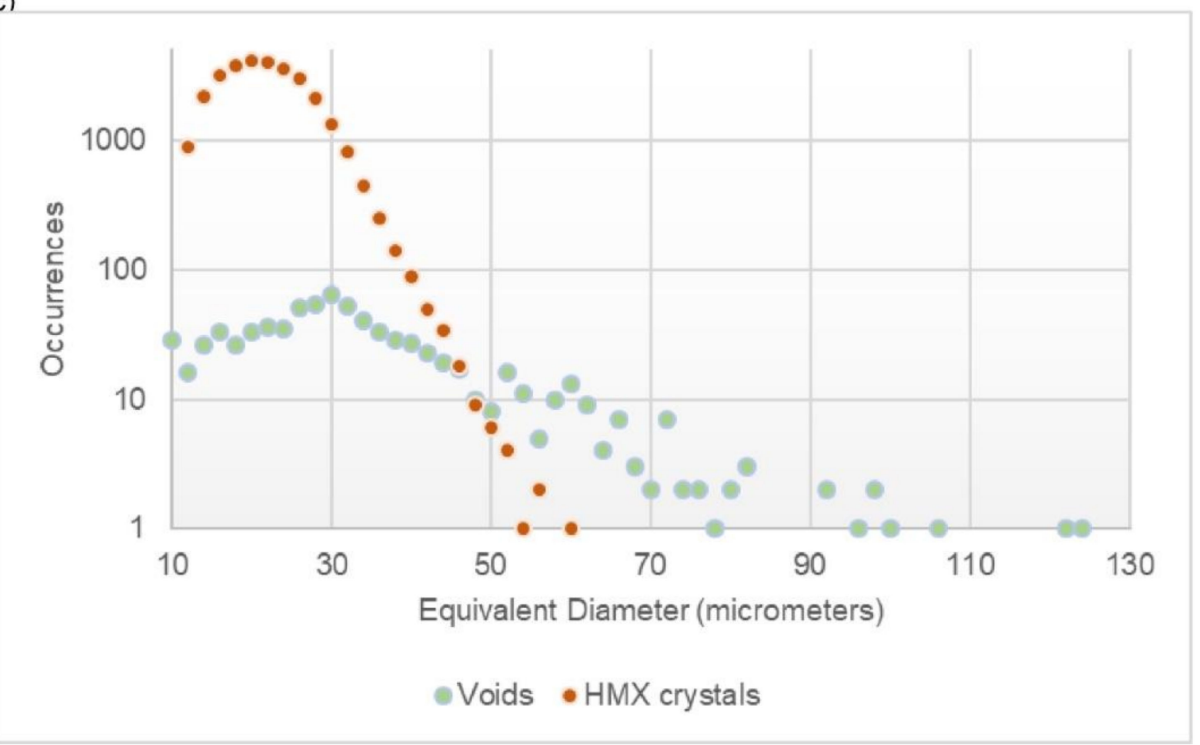

Figure 2. 3D rendering of the voids (a) and the crystals (b) within the HMX-HTPB plastic-bonded explosives (PBX) system. The voids and the crystals are colored by their equivalent diameter with the graph (c), a plotting of a histogram of their sizes. The equivalent diameter is the diameter of a sphere with the same volume as the object.

Figure 3 compares the other six PBX formulations with a single reconstructed slice taken in one glance, with detailed comparisons being shown in later figures. All images have only been altered with minor brightness and contrast adjustments. While each material has approximately the same concentration of the binder, there are obvious differences in image contrast between the various materials. This is likely due in large part to crystal size distribution and similarity in density between the crystals and binders. HMX has a density of $1.905 \mathrm{~g} / \mathrm{cm}^{3}$ and TATB has a density of $1.937 \mathrm{~g} / \mathrm{cm}^{3}$. Viton A has a density of $\approx 1.8 \mathrm{~g} / \mathrm{cm}^{3}$, Estane is $\approx 1.1 \mathrm{~g} / \mathrm{cm}^{3}$, and the plasticized binders in PBX 9501 and PBX 9404 are $\approx 1.2 \mathrm{~g} / \mathrm{cm}^{3}$ and $1.5 \mathrm{~g} / \mathrm{cm}^{3}$, respectively. The relatively large density differences between HMX and the non-Viton binders probably contribute to the clarity of the images. For PBX 9502, the Kel-F binder is actually slightly higher in density $\left(2.02 \mathrm{~g} / \mathrm{cm}^{3}\right)$ than the TATB crystals, meaning it shows up as a lighter grayscale value. Both PBX 9501 and PBX 9502 were studied in more detail here to attempt to segment the binder, crystals, and voids. 
a)

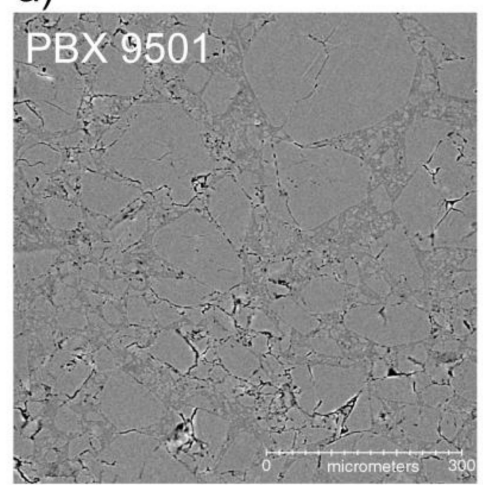

d)

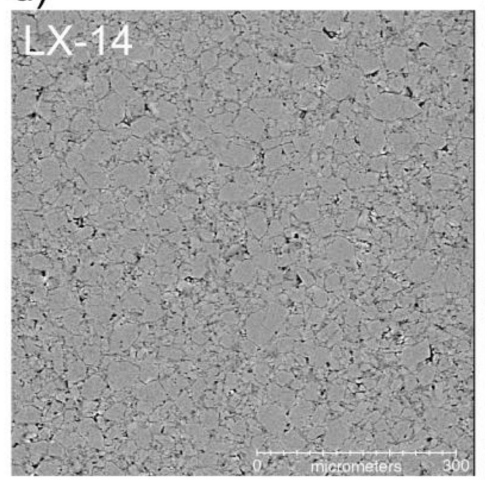

b)

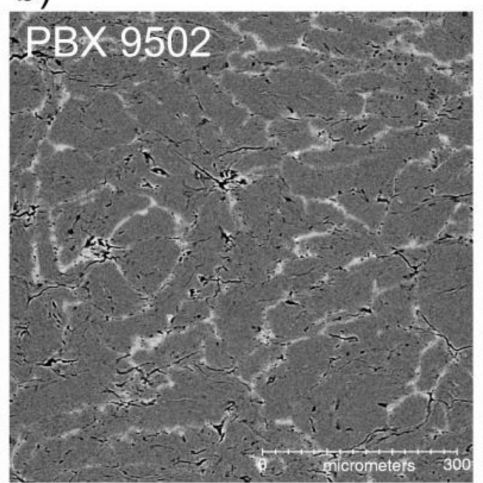

e)

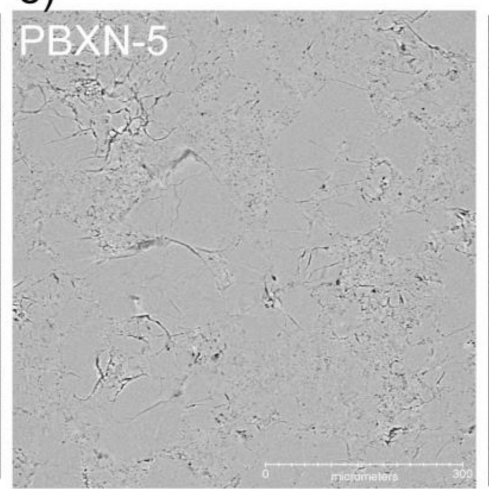

c)

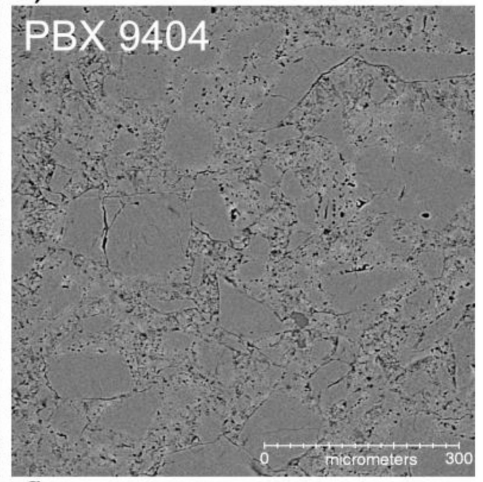

f)

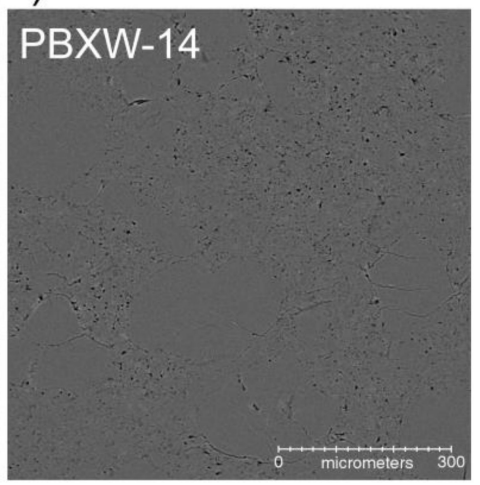

Figure 3. Reconstructed $\mu \mathrm{CT}$ slice images from the six plastic-bonded explosive materials. PBX 9501 (a), PBX 9502 (b), PBX 9404 (c), LX-14 (d), PBXN-5 (e), and PBXW-14 (f). The images are through the center of the high explosive cylinder and are nearly completely free of all imaging artifacts.

\subsubsection{Segmentation of PBX 9501 and PBX 9502}

PBX 9501 and PBX 9502 are the most commonly studied PBX materials at Los Alamos, and as mentioned earlier, there exist many research efforts to link experimental measurements to theoretical and computational studies at multiple time and length scales. Therefore, an effective method for the segmentation of the PBX materials into their constituent parts would be of high value. To our knowledge, phase segmentation based on direct microstructural interrogation has never before been accomplished in these materials.

Segmentation of the reconstructed PBX 9501 was attempted with a variety of techniques. As mentioned before, our human brains are quite adept at picking out patterns within the images and detecting the crystals; however, a line profile of the grayscale values through the dataset only shows noise when passing through crystals and binders. Upon importing into Avizo, the data were filtered with the edge-preserving smoothing filter (90k as the optimal contrast value). At this point, the segmentation for voids is a relatively straightforward grayscale selection. However, the minor density difference between the crystals and the binder means that they cannot be adequately segmented based on a single image. Figure 4 shows a single reconstructed slice of both HMX-HTPB and PBX 9501 with a line profile through the composite. As can be seen, the grayscale values between the crystals and binder are adequate for the segmentation of the HMX-HTPB seen in Figure 2, but they are not adequate for the PBX 9501; more advanced data acquisition and processing are required. 
a)

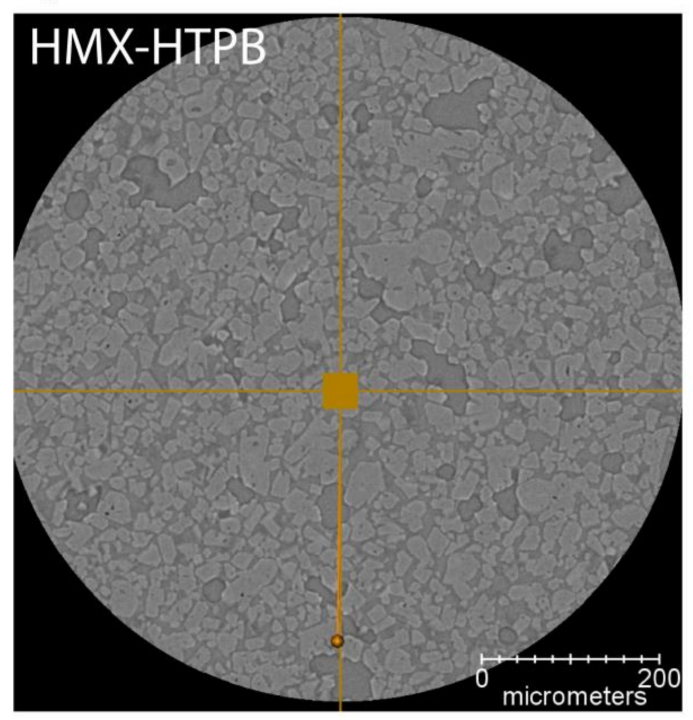

b)

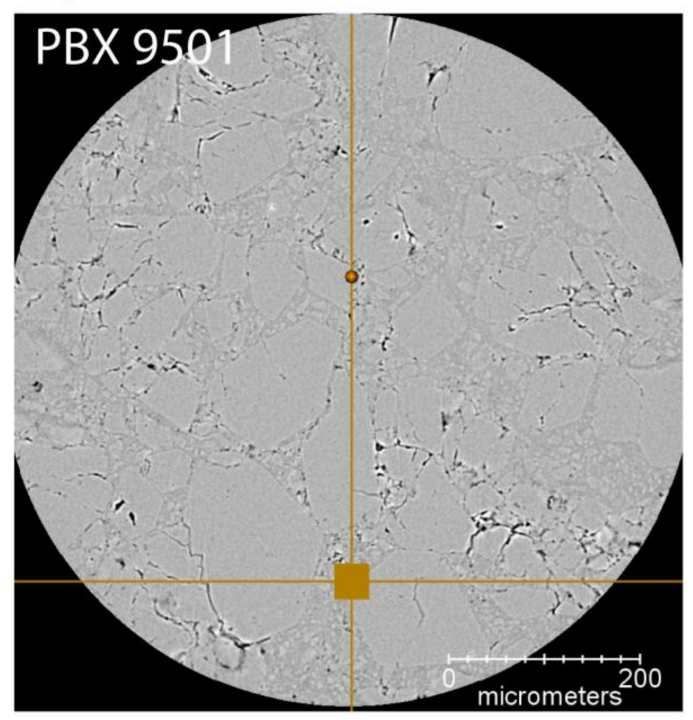

c)

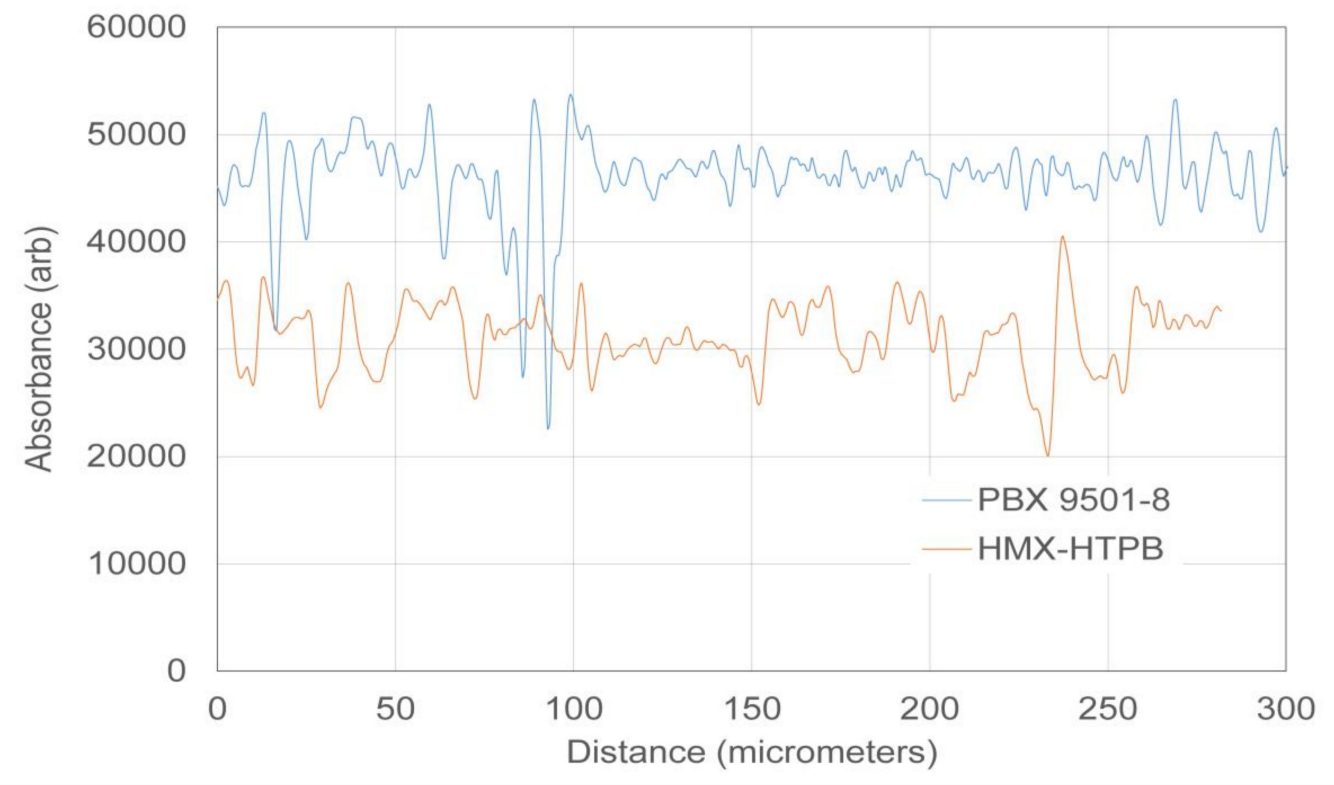

Figure 4. Reconstructed slice through HMX-HTPB (a) and PBX 9501 (b) composite comparing the gray scale differences between the crystals and the binder. Line profiles extracted from the images show the improved signal-to-noise in the HMX-HTPB sample (c).

In order to try to improve the grayscale values between the crystals and the binder, most of the samples were imaged using a dual-energy modality. This modality images the samples at two different X-ray energies. The sample must fit within the field of view of the image; therefore, these images were at a lower resolution than the images shown in the previous section at $3.78 \mu \mathrm{m}$. The two images rely on the difference in absorption processes between the photoelectric effect at low energies and Compton scattering at higher energies. To obtain the greatest separation in X-ray absorption, the two images of the samples were run at low energy $(30 \mathrm{kVp})$ and again with the source at high energy $(160 \mathrm{kVp})$ and a filter (LE5) to have an average photon energy of $\approx 70 \mathrm{kV}$, as seen in Figure $5 \mathrm{a}, \mathrm{b}$. These two images were then imported into the Zeiss Dual-Energy Contrast visualizer software. The noise reduction filter was applied once to the low energy image and twice to the high energy image. The filtered data were 
plotted as a 2D histogram as seen in Figure 5c, which shows a plotting of the grayscale value of the low energy image versus the grayscale value of the high energy image for each voxel. Four "hot spots" are noted on the plot. They represent the air around the sample (not shown, as the reconstructed slices are zoomed in to aid the reader in seeing the crystals), the interface of the air to the sample and the voids (both on the upper left of the plot), and the voxels representing the grayscale value of the crystals and binder, which are represented by the hot spots in the lower right quadrant of 5c.. Ideally, the points on the histogram are completely separated from each other; they were selected using the tool and then exported as a.txm file for plotting in a rendering package. For this study, there is some overlap in the regions representing the crystals and the binder that were selected and exported. A slice through the image of the crystals is shown in Figure $5 \mathrm{~d}$. This technique measures the crystals as occupying a percent volume of $57.6 \%$.
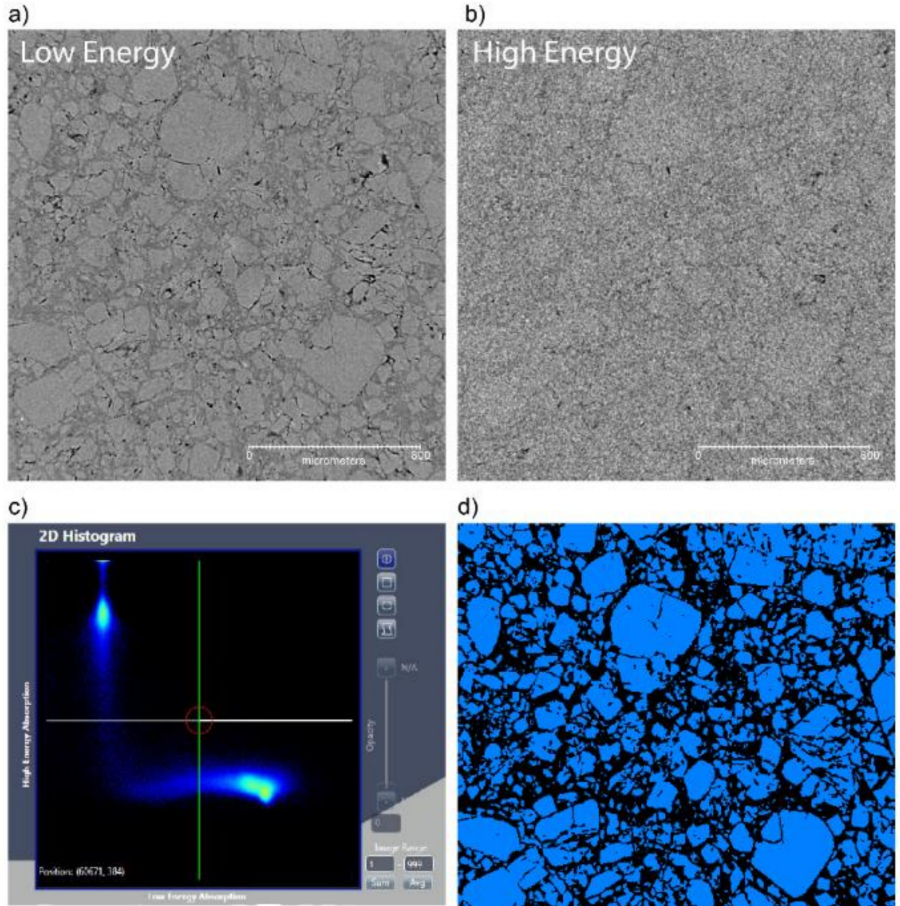

d)

e)

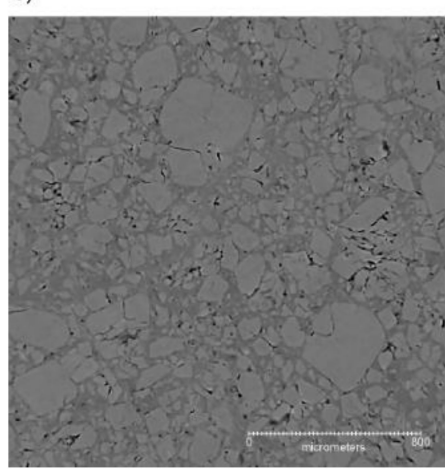

f)

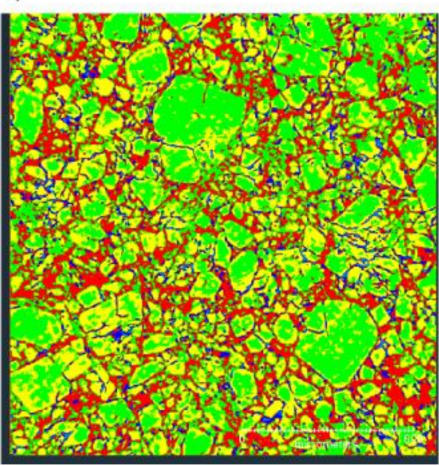

g)

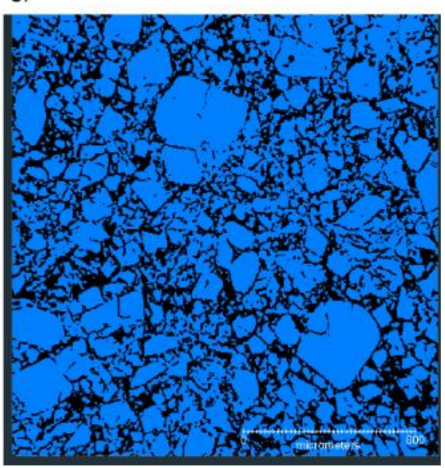

Figure 5. Segmentation attempts of PBX 9501 images using two different energies for the dual energy imaging technique, where (a) and (b) are the low energy and high energy reconstructed slices, and (c) is the 2D correlation plot of the high and low energy grayscale values used to select the crystals (d). The blob in the lower right is two unresolved spots; one represents the crystals, and the other is the binder; (e) is the output subpixel aligned low energy (SALE) image, sharpened, then segmented using the auto intensity calibration (f), and then finally segmented for the crystals $(\mathbf{g})$. 
A second composite dual-energy image was exported out of the dual-contrast visualizer as a subpixel aligned low energy (SALE) image. This image was then imported into Avizo, and a sharpening filter was applied. This 3D image was then cropped to only contain the sample and segmented for five regions using auto intensity correlation (Figure 5f). Two of these regions represent the crystals and the interface to the crystals to the binder (Figure $5 \mathrm{~g}$ ). This technique measures the crystals as occupying a percent volume of $57.2 \%$. This excellent agreement between the two techniques seems to indicate their robustness. The sample contained $3 \%$ of the measured void volume.

A theoretical maximum density (TMD) of the sample of PBX 9501 should be $92.7 \%$ by volume HMX, 3.9\% by volume Estane, and 3.3\% by volume plasticizer. Using either segmentation technique, the calculated crystal content underestimates the reality by about a third. The most likely reason for this underestimation is that a significant fraction of the HMX crystals are too fine to be adequately distinguished from the binder given the spatial resolution. The HMX size distribution is approximately 3:1 coarse to fine, where "fine" includes any particles under $45 \mu \mathrm{m}$ equivalent diameter [36]. The voxel size of the dual-energy approach was $3.78 \mu \mathrm{m}$, with a spatial resolution of $\approx 12 \mu \mathrm{m}$ (assuming a 3 voxel requirement to define an edge). This means that the largest of the fine crystals detected would only be 10-12 pixels across. Moreover, many of the fine crystals are in fact well below $45 \mu \mathrm{m}$ [37]. It is difficult to distinguish crystals at only a few pixels across with any confidence. Another contributing factor could be that the crystal boundaries are not sharply defined from the binder due to gradient composition or intermixing, which is known to be possible in PBX 9501, albeit at finer scales [38]. Gradual changes in grayscale values make it more difficult for the software to distinguish edges, possibly leading to the underestimation of true crystal volume.

Unlike PBX 9501, segmentation in PBX 9502 was relatively straightforward because the binder shows up so clearly in the images (Figure 3). This is probably due to two effects. First, the Kel-F binder has chlorine and fluorine while the TATB is only organic (CHNO). Second, the Kel-F is believed to preferentially form shells around binder-poor TATB agglomerates during the slurry formulation process rather than evenly coating the TATB crystals. While those shell-agglomerate particles (also known as molding prills) are typically at the millimeter scale during shipping and handling, compacted samples of this type of material are known to retain some residual prill structure even when pressed to high density [39-41]. The dark clumps in between the binder are not likely to be individual crystals of TATB, since the TATB used in PBX 9502 is effectively identical in particle size to the neat TATB studied here $(\approx 20 \mu \mathrm{m})$, which is presented later. The dark regions here are likely agglomerates of TATB crystals, indicating that there are multiple length scales of interest when characterizing the PBX 9502 microstructure; that is, the individual crystal scale and the crystal agglomerate/molding prill scale. This finding also reinforces some recent modeling approaches in the literature that account for multiple length scales to match experimental data $[42,43]$.

The contrast in the PBX 9502 sample is such that the segmentation into crystal, binder, and voids was possible using the machine software. To our knowledge, this is the first time that a microstructural segmentation of such a highly loaded explosive has ever been accomplished. Figure 6 shows renderings of the binder distribution and the void distribution, with the latter color-coded by equivalent diameter. Among other measurements, this type of segmentation enables calculation of the relative volume fractions of each constituent. Of course, the calculation is limited by the voxel size of the measurement, but rough estimates are easily obtained. Here, the segmentation calculates the binder percent as $4.68 \%$ by volume, which can be converted to a weight percent of $\approx 4.9 \%$, essentially identical to the desired formulation. The void content is measured to be $3 \%$ with a standard deviation of $1 \%$. Based on the pressing conditions, the estimated void content for this formulation is $\approx 2.5 \%$ and is thus within the standard deviation for PBX 9502. 
a)

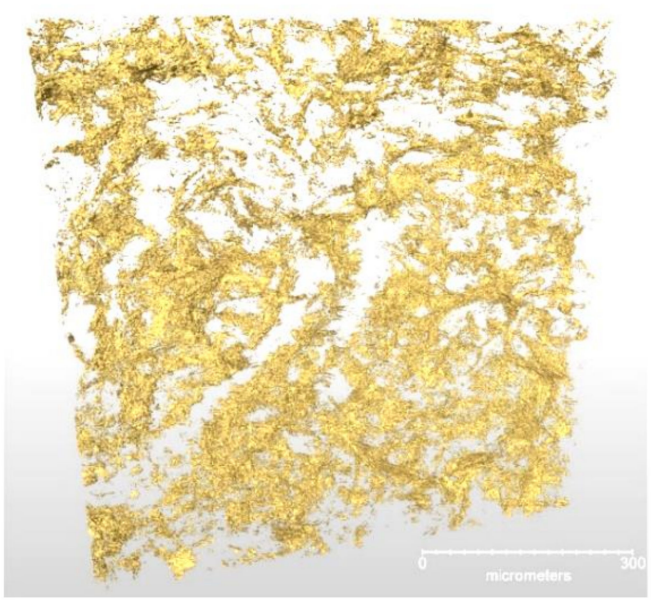

b)

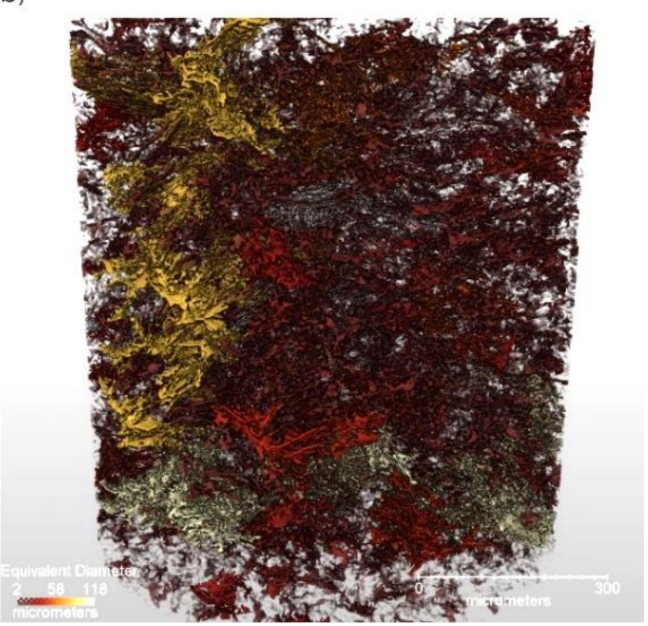

Figure 6. Segmented partial volumes of the measured PBX 9502 microstructure, showing binder distribution (a) and void size distribution (b). Some concentrations of voids can be seen, probably indicating cracks or TATB crystal boundaries.

\subsubsection{Comparison of Three Highly-Loaded HMX Formulations}

Figure 7 shows selected regions of three similar PBXs to highlight the influence of microstructural features on the usefulness of this technique. Specifically, these three materials have slightly different crystal-binder density ratios, HMX content, and HMX particle sizes. LX-14 is shown in Figure 7a, having a very broad particle size distribution, and perhaps because of this it seems to have a slightly higher concentration of voids than the other PBXs. PBX 9501 (Figure 7b) is similar to LX-14 in that it has nearly identical HMX content and uses an Estane binder, but the binder is plasticized and the particle size distribution is a more well-defined 3:1 coarse-to-fine ratio. PBX 9404 (Figure 7c) is similar to PBX 9501 in HMX particle size distribution but has a nitrocellulose binder that is closer in density to the HMX crystals than is to the Estane. In both of the latter PBX materials, the large HMX crystals often present internal cracks, likely due to their brittle nature, which manifests when absorbing a high amount of the pressure during the compaction process.

a)

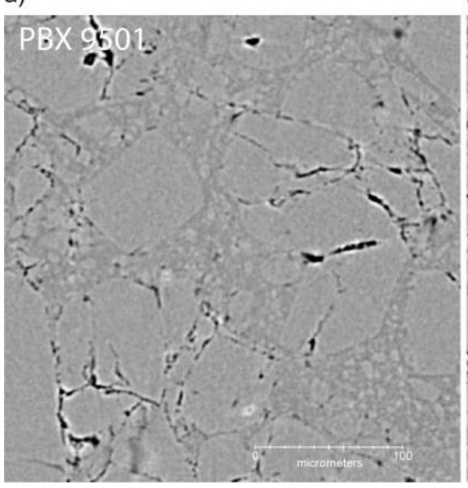

b)

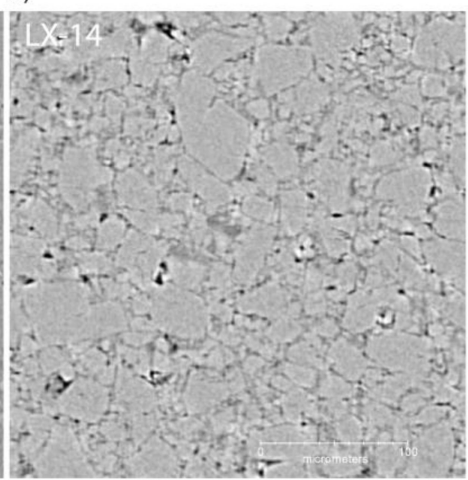

c)

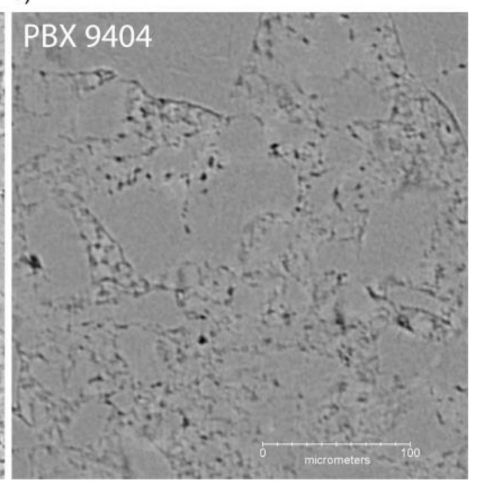

Figure 7. $\mu \mathrm{CT}$ reconstructed slices of LX-14 (a), PBX 9501 (b), and PBX 9404 (c) microstructures.

The differences in the ability of dual-energy $\mu \mathrm{CT}$ to characterize these materials is instructive. The instrument resolution for these three samples was identical. The microstructure "resolution", which is a function of the material properties and the instrument resolution, appears to be better for LX-14 and PBX 9501 than PBX 9404. The most likely contributor to this is the binder-HMX density differences, where PBX 9404 has the smallest difference. We also note that HMX is shown to have the ability to intermix in nitrocellulose [44], so the material processing conditions may also lead to 
rounded crystal edges or HMX-nitrocellulose intermixing, further obfuscating the image. The PBX 9501 appears to have the most well-defined microstructure, possibly due to the larger particle size distribution as compared to LX-14.

\subsection{HE Materials without a Binder}

Figure 8 compares the three HE materials that do not have a polymer binder. Composition B (Figure 8a,d) and Octol (Figure 8b,e) use TNT as the matrix, with RDX and HMX filler HE respectively, and some differentiation between the TNT and the filler HE can be seen. The TATB (Figure 8c,f) images are not particularly easy to interpret by eye, but some grain boundaries can be observed, and certainly the distribution of voids can be characterized. The average particle size calculable for TATB in this case is on the order of $20 \mu \mathrm{m}$, which is in a similar size regime to TATB specifications and other studies $[39,45,46]$. This small particle size reinforces the PBX 9502 findings, where crystal agglomeration between distinct binder regions must be happening because their sizes are much larger than the small crystals found here.

a)

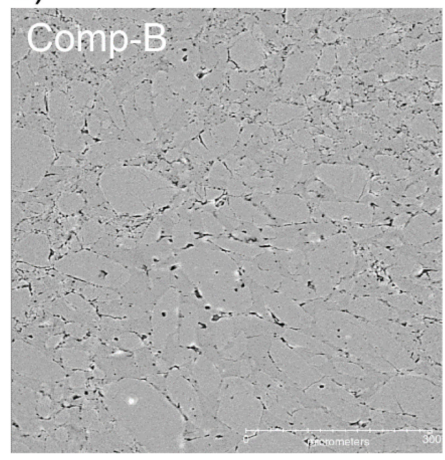

d)

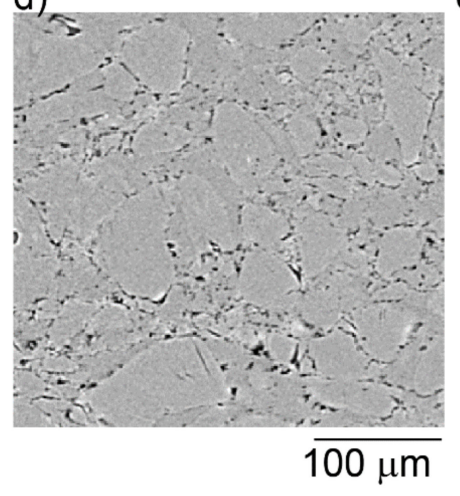

b)

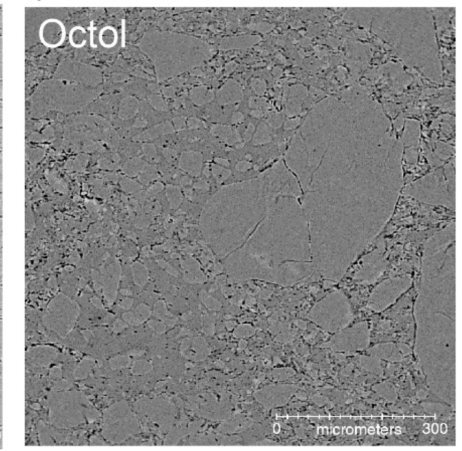

e)

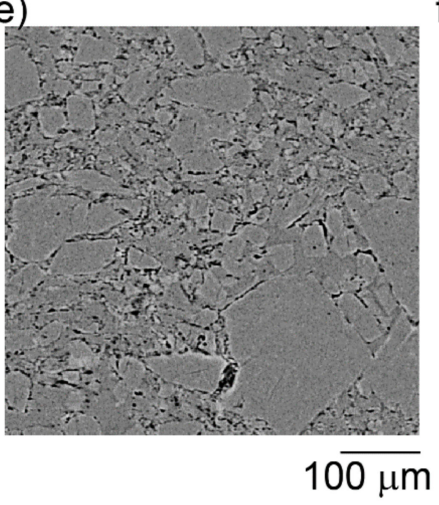

c)

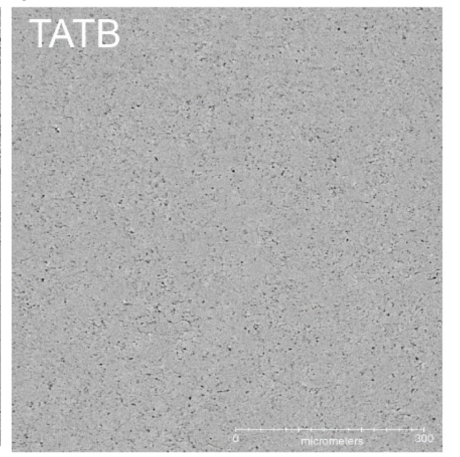

f)

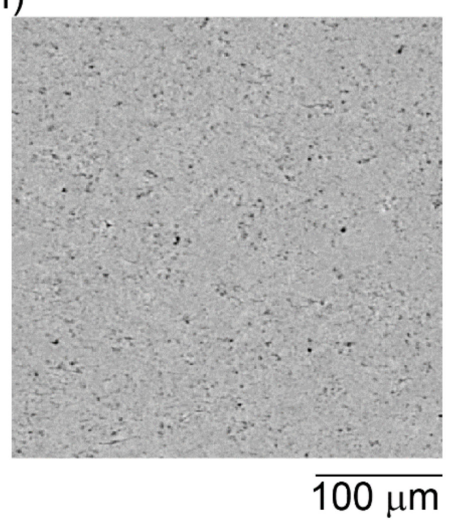

Figure 8. Typical $\mu \mathrm{CT}$ reconstructed slices of the microstructure for Composition B (a,d), Octol (b,e), and TATB $(\mathbf{c}, \mathbf{f})$ at two fields of view.

For the two TNT-based samples, the larger crystals can be distinguished from the matrix by eye, but the only segmentable feature is the void structure. The void structure of the TATB sample is also easily measured. Figure 9 shows the void structure of Composition B. Within the limits of spatial resolution, some of the "voids" appear as elongated planes and are probably more accurately described as cracks. We note that the processing method used here (pressed to shape rather than melt-cast to shape) may have some influence on the measured properties. 


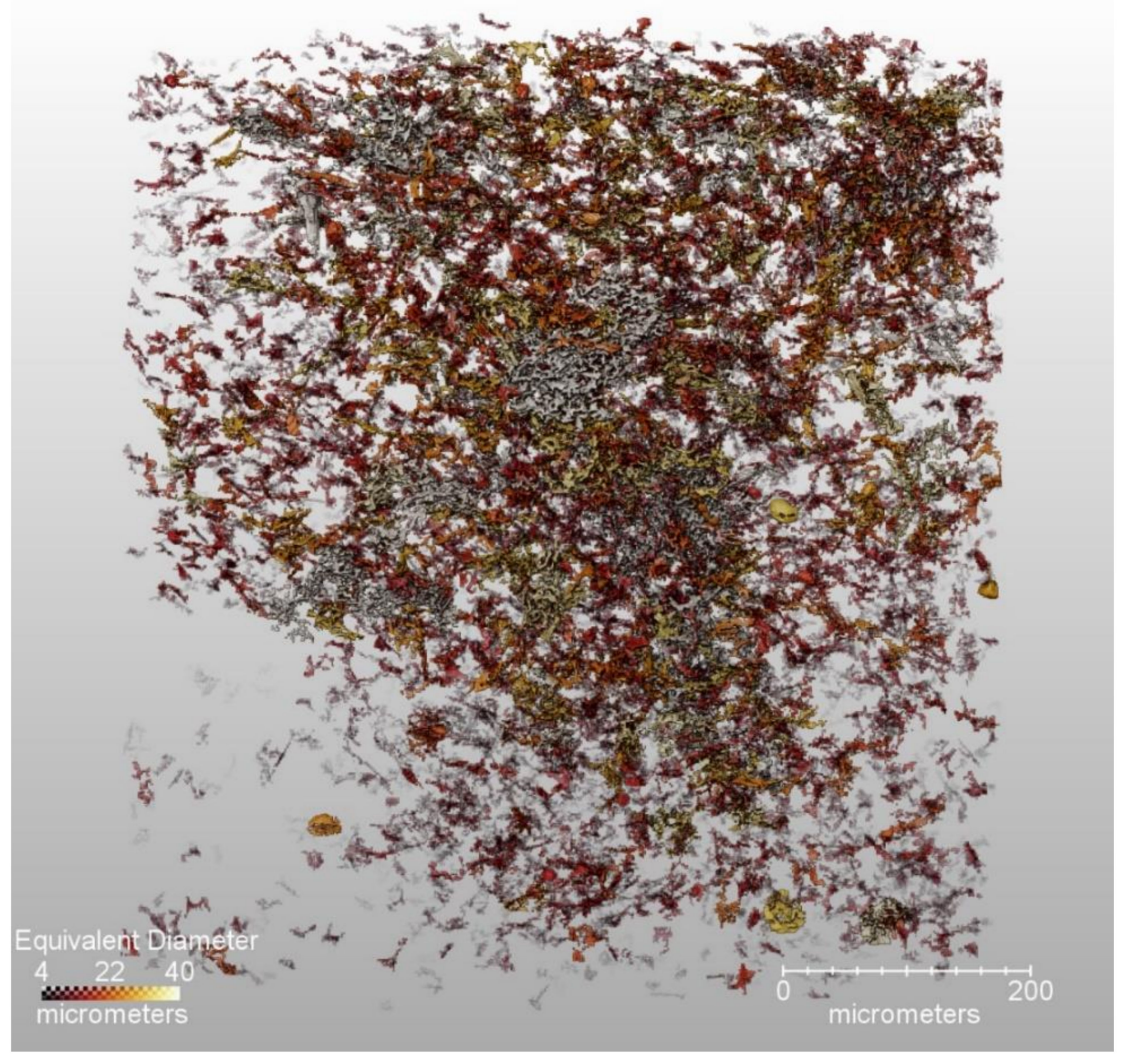

Figure 9. 3D rendering of the voids within the Composition B explosive, colored by equivalent diameter. The largest voids are about $40 \mu \mathrm{m}$ in equivalent diameter, but in reality, they are mostly flat planes throughout the sample. The voids are not evenly distributed and occupy $2 \%$ of the total volume.

\section{Discussion}

\subsection{New State-of-the-Art for Full PBX Segmentation}

This comprehensive effort to measure microstructural features in HEs with state-of-the-art laboratory $\mu \mathrm{CT}$ equipment and software demonstrates some important advances but also shows just how far is left to go. From a mesoscale modeling perspective, fully phase-segmentable datasets are needed for direct implementation into simulations. For the PBX materials, this means a complete segmentation of each constituent material, along with the voids. For the HEs without polymers, ideally both voids and grain boundaries would be segmentable. Here, we have successfully segmented two of the ten measured HEs to this level of precision. While success with the HMX-HTPB formulation was expected as it was characterized before, the full segmentation of PBX 9502 is very exciting. To our knowledge, this is the first time ever that a "real" (i.e., highly loaded, nonengineered, nonoptimized) explosive was segmented into constituent phases. A third HE, PBX 9501, was partly segmentable by using two different analysis techniques, especially the larger crystals, but work is underway to develop other segmentation techniques to be able to fully use current $\mu \mathrm{CT}$ scans. It is possible that a focused numerical effort, using machine learning or other advanced segmentation technology, could fully segment the PBX 9501 dataset. The segmented $\mu$ CT data for these three HE materials are available for download in the Supplementary Materials to aid in future mesoscale simulations.

\subsection{Measurements of Voids and Implications for Modeling}

For the other materials, segmentation was generally limited into voids vs. solids. Void size distributions do occasionally reveal some interesting features of the microstructure, such as grain 
boundaries or cracks, and there are many mesoscale modeling approaches that could use this data as is. However, the obvious nonhomogeneity of the void distributions (Figures 2, 6 and 9) also has important implications for HE detonation modeling at the continuum scale.

For modeling to be tractable for computing detonation in charges that are very large compared to the HE microstructure, detonation reactive flow models (RFMs) must treat the explosive as a continuum. Accordingly, they utilize a reaction rate law that is expressed in terms of continuum variables. Nevertheless, in order to capture underlying heterogeneous reaction mechanisms, continuum reaction rate laws must suitably reflect the microscopic driving mechanisms. The exercise of distilling the essence of heterogeneous reaction mechanisms into a continuum rate law is called homogenization.

The only formal homogenization problem that has been performed to date considers a collection of randomly-placed hot-spot nucleation sites within a considered fluid element. Just as for other multiphase fluid models, the element is assumed to contain enough nucleation sites to be statistically representative, yet still small compared to the reaction zone thickness. Spherical burn waves grow from the nucleation sites, consuming the interstitial reactants: This early burn-phase comprises so-called "hole burning" or "progressive burn," terminology borrowed from the propellant community. The essential problem is how these burn waves coalescence. The late consumption of material has a "grain burning" or "regressive burn" morphology, and intermediate phases are transitional forms [47-49].

It is interesting and perhaps a bit surprising that the problem has a simple analytic solution, which was first discovered and derived in essentially maximum generality by Kolmogorov in 1937 -the original application being heterogeneous phase changes in metals. Within a few years, a subset of the same result (i.e., the impulsive nucleation limit) was independently derived by Avrami, using an alternative nonstatistical approach [50]. In the field of material science, the result is now known as the Johnson-Mehl-Avrami-Kolmogorov (JMAK) equation.

The JMAK model was first used in the context of detonation by Hayes, who independently derived the impulsive nucleation limit in 1983 [51]. The JMAK model was first invoked as an RFM component by Nichols, who once again independently derived the result in 2002 [52]. Nichols called the result the statistical hot spot (SHS) model, which is the name by which it continues to be known in the detonation community.

The SHS prescription is now used by several modern RFMs, including the Los Alamos Scaled Uniform Reactive Flow (SURF) model. When Menikoff and Shaw set about to calibrate and validate SURF [53], they observed that the 2D SHS variant (i.e., expanding and coalescing circles or parallel cylinders) yielded better agreement with detonation test data than did the 3D variant (i.e., expanding and coalescing spheres).

The reason for this curious observation has been a matter of some speculation; however, the void distribution shown in Figure $6 \mathrm{~b}$ illustrates why such behavior is perhaps to be expected. Here, it appears that voids tend to concentrate at those crystal interfaces into which the binder has been unable to flow. The result is a collection of sheet structures resembling a bowl of cornflakes. As these are essentially $1 \mathrm{D}$ structures embedded in $3 \mathrm{D}$ space, it is not surprising that their coalescence would resemble the 2D SHS problem more than the 3D problem. Hill has recently suggested that, for RFM purposes, SHS should be expressed in terms of an optimal noninteger dimensionality, which reflects underlying structures of this type [54].

It is not our purpose to delve too deeply into the complex subject of microstructural effects upon detonation; however, this example serves to give a feeling of how and why they are important, and how detailed pictures such as those of Figures $6 \mathrm{~b}$ and 9 can fundamentally affect one's views on modeling. One simply cannot look at these pictures and propose spherical void distributions.

\subsection{Future Work with Non-Phase-Segmentable HE}

It was noted earlier that optical microscopy is often used to characterize HE microstructure and that micrographs are occasionally digitized or otherwise used as reference points for synthetic 
microstructures in simulations. Another useful finding of this present work is that almost all of the HE samples were at least able to be visualized at a similar quality to most optical microscopy. Grain boundaries could be observed by eye, so grain size and distribution of sizes could be manually calculated from $\mu \mathrm{CT}$ slices using stereological approaches in a similar way that micrographs would be used. A digitization or manual tracing of at least the larger grains should be successful. This demonstrates that the current $\mu \mathrm{CT}$ capability is at least as useful as conventional optical microscopy while requiring no sample preparation, which is important both in terms of time and effort and also for eliminating the possibility of damaging the microstructure when polishing. It is also important to note that polishing a 2D surface removes any voids measurable at the surface, so estimates of void content from microscopy may be inaccurate. As mentioned earlier, even manual or semiautomatic microstructural characterization is useful for determining relationships between the structure of a given $\mathrm{HE}$ to all manner of reaction and detonation phenomena.

As technology in both image collection and image analysis improves, as seen in the dual-energy imaging technique demonstrated here, we will likely be able to segment the various constituents of each of the PBX materials, though the melt-cast materials will remain difficult due to the density similarities of the constituents. Future approaches could include doping one material with a higher $\mathrm{Z}$ element to enhance the contrast, though obviously this has drawbacks in terms of changing the other sample properties (i.e., doped materials may not consolidate identically during pressing and will affect mechanical properties). Future PBX materials with naturally different elemental composition would also lend themselves to a more accurate 3D measurement of the microstructural differences between crystals and the binder.

\section{Conclusions}

Characterization of the microstructure of several classes of high explosive materials was performed using state-of-the-art X-ray microcomputed tomographic techniques. Segmentation of these composite materials into their constituent phases was attempted using several techniques and showed great promise for at least a few of the materials. PBX 9502 was able to be segmented so effectively that the measured composition matched reality, while PBX 9501 segmentation was moderately effective. For the other materials, software segmentation could be used to segment voids from solid materials, but segmentation between solid phases was not possible. However, accurate representations of voids and their size distribution should still be useful for certain modeling scenarios even if the solid phases are indistinguishable from each other. Each type of data (full tomographic detail, general microstructural characterization, and void size distribution statistics) should be implementable for a variety of simulations. Microstructural images were of similar quality to typical optical microscopy, providing useful detail while minimizing sample preparation and eliminating the possibility of introducing defects during preparation (e.g., cutting and polishing). Overall, this investigation demonstrated the ability to characterize microstructural features such as voids, cracks, crystal sizes, and crystal agglomeration across a wide variety of relevant explosive materials. Such information is critical for future modeling and simulation efforts.

Supplementary Materials: The following are available online at dx.doi.org/10.25583/1658864—Figure S1: Reconstructed TIFFs of HMX-HTPB; Figure S2: Reconstructed TIFFs of segmented HMX-HTPB; Figure S3: Reconstructed TIFFs of PBX 9501 dual energy SALE image; Figure S4: Reconstructed TIFFs of PBX 9501 after segmenting with Intensity Auto Classification; Figure S5: Reconstructed TIFFs of PBX 9502; Figure S6: Reconstructed TIFFs of PBX 9502 Segmented for binder; Video S1: Slice-through of HMX-HTPB; Video S2: Slice-through of PBX 9501, Video S3: Slice-through of PBX 9502.

Author Contributions: Conceptualization, J.D.Y., B.M.P., and L.G.H.; methodology, A.L.D., L.A.K., and B.M.P.; formal analysis, L.A.K. and B.M.P.; investigation, J.D.Y., L.A.K., and B.M.P.; resources, A.L.D. and J.D.Y.; data curation, B.M.P.; writing-original draft preparation, J.D.Y. and B.M.P..; writing-review and editing, all authors; visualization, B.M.P., L.A.K., and J.D.Y.; project administration, J.D.Y. and L.G.H.; funding acquisition, J.D.Y. and L.G.H. All authors have read and agreed to the published version of the manuscript. 
Funding: This work was supported by the US Department of Energy through the Los Alamos National Laboratory. Los Alamos National Laboratory is operated by Triad National Security, LLC, for the National Nuclear Security Administration of U.S. Department of Energy (Contract No. 89233218CNA000001). Specifically, the authors wish to acknowledge Delivery Environments (Antranik Siranosian) and Campaign 2 (Dana Dattelbaum) for funding this work.

Conflicts of Interest: The authors declare no conflict of interest. The funders had no role in the design of the study; in the collection, analyses, or interpretation of data; in the writing of the manuscript, or in the decision to publish the results.

\section{References}

1. Khasainov, B.A.; Ermolaev, B.S.; Presles, H.N.; Vidal, P. On the effect of grain size on shock sensitivity of heterogeneous high explosives. Shock Waves 1997, 7, 89-105. [CrossRef]

2. Bellitto, V.J.; Melnik, M.I.; Sherlock, M.H.; Chang, J.C.; O'Connor, J.H.; Mackey, J.A. Microstructure effects on the detonation velocity of a heterogeneous high-explosive. J. Energy Mater. 2018, 36, 485-492. [CrossRef]

3. Parfenov, A.; Voskoboinikov, I.J.C. Low-velocity detonation of powdered explosives. Combust. Explos. Shock Waves 1969, 5, 240-244. [CrossRef]

4. Hill, L.G.; Aslam, T.D. Detonation shock dynamics calibration for PBX 9502 with temperature, density, and material lot variations. In Proceedings of the Fourteenth International Detonation Symposium, Office of Naval Research, Coeur d'Alene, ID, USA, 1 January 2010; pp. 779-788.

5. Dobratz, B.M. The Insensitive High Explosive Triaminotrinitrobenzene (TATB): Development and Characterization-1888 to 1994; LA-13014-H; Los Alamos National Lab: Los Alamos, NM, USA, 1995.

6. Barua, A.; Zhou, M. A Lagrangian framework for analyzing microstructural level response of polymer-bonded explosives. Modell. Simul. Mater. Sci. Eng. 2011, 19, 055001. [CrossRef]

7. Barua, A.; Kim, S.; Horie, Y.; Zhou, M. Prediction of probabilistic ignition behavior of polymer-bonded explosives from microstructural stochasticity. J. Appl. Phys. 2013, 113, 184907. [CrossRef]

8. Perry, W.L.; Clements, B.; Ma, X.; Mang, J.T. Relating microstructure, temperature, and chemistry to explosive ignition and shock sensitivity. Combust. Flame 2018, 190, 171-176. [CrossRef]

9. Rai, N.K.; Udaykumar, H.S. Mesoscale simulation of reactive pressed energetic materials under shock loading. J. Appl. Phys. 2015, 118, 245905. [CrossRef]

10. Salyer, T.R. The effects of PBX 9502 ratchet growth on detonation failure as determined via the LANL failure cone test. AIP Conf. Proc. 2012, 1426, 243-246.

11. An, C.W.; Guo, X.D.; Song, X.L.; Wang, Y.; Li, F.S. Preparation and safety of well-dispersed rdx particles coated with cured HTPB. J. Energy Mater. 2009, 27, 118-132. [CrossRef]

12. Kasprzyk, D.J.; Bell, D.A.; Flesner, R.L.; Larson, S.A. Characterization of a Slurry Process Used to Make a Plastic-Bonded Explosive. Propellants Explos. Pyrotech. 1999, 24, 333-338. [CrossRef]

13. Paraskos, A.J. Energetic Polymers: Synthesis and Applications. In Energetic Materials: From Cradle to Grave; Shukla, M.K., Boddu, V.M., Steevens, J.A., Damavarapu, R., Leszczynski, J., Eds.; Springer International Publishing: Cham, Switzerland, 2017; pp. 91-134.

14. Dattelbaum, D. Equations of State of Binders and Related Polymers. In Static Compression of Energetic Materials; Peiris, S.M., Piermarini, G.J., Eds.; Springer: Berlin, Germany, 2008.

15. Li, J.-S.; Chen, J.-J.; Hwang, C.-C.; Lu, K.-T.; Yeh, T.-F. Study on Thermal Characteristics of TNT Based Melt-Cast Explosives. Propellants Explos. Pyrotech. 2019, 44, 1270-1281. [CrossRef]

16. Cooper, P.W.; Kurowski, S.R. Introduction to the Technology of Explosives; John Wiley and Sons: Hoboken, NJ, USA, 1996.

17. Peterson, P.D.; Fletcher, M.A.; Roemer, E.L. Influence of Pressing Intensity on the Microstructure of PBX 9501. J. Energy Mater. 2003, 21, 247-260. [CrossRef]

18. Skidmore, C.B.; Phillips, D.S.; Asay, B.W.; Idar, D.J.; Howe, P.M.; Bolme, D.S. Microstructural effects in PBX 9501 damaged by shear impact. AIP Conf. Proc. 2000, 505, 659-662.

19. Knepper, R.; Tappan, A.S.; Wixom, R.R.; Rodriguez, M.A. Controlling the microstructure of vapor-deposited pentaerythritol tetranitrate films. J. Mater. Res. 2011, 26, 1605-1613. [CrossRef]

20. Banerjee, B.; Adams, D.O. On predicting the effective elastic properties of polymer bonded explosives using the recursive cell method. Int. J. Solids Struct. 2004, 41, 481-509. [CrossRef] 
21. Benson, D.J.; Conley, P. Eulerian finite-element simulations of experimentally acquired HMX microstructures. Modell. Simul. Mater. Sci. Eng. 1999, 7, 333-354. [CrossRef]

22. Siviour, C.R.; Laity, P.R.; Proud, W.G.; Field, J.E.; Porter, D.; Church, P.D.; Gould, P.; Huntingdon-Thresher, W. High strain rate properties of a polymer-bonded sugar: Their dependence on applied and internal constraints. Proc. R. Soc. A Math. Phys. Eng. Sci. 2008, 464, 1229-1255. [CrossRef]

23. Manner, V.W.; Yeager, J.D.; Patterson, B.M.; Walters, D.J.; Stull, J.A.; Cordes, N.L.; Luscher, D.J.; Henderson, K.C.; Schmalzer, A.M.; Tappan, B.C. In situ imaging during compression of plastic bonded explosives for damage modeling. Materials 2017, 10, 638. [CrossRef]

24. Kort-Kamp, W.J.M.; Cordes, N.L.; Ionita, A.; Glover, B.B.; Duque, A.L.H.; Perry, W.L.; Patterson, B.M.; Dalvit, D.A.R.; Moore, D.S. Microscale electromagnetic heating in heterogeneous energetic materials based on x-ray computed tomography. Phys. Rev. Appl. 2016, 5, 044008. [CrossRef]

25. Willey, T.M.; Lauderbach, L.; Gagliardi, F.; van Buuren, T.; Glascoe, E.A.; Tringe, J.W.; Lee, J.R.I.; Springer, H.K.; Ilavsky, J. Mesoscale evolution of voids and microstructural changes in HMX-based explosives during heating through the $\beta-\delta$ phase transition. J. Appl. Phys. 2015, 118, 055901. [CrossRef]

26. Chen, N.; Koker, M.K.A.; Uzun, S.; Silberstein, M.N. In-situ X-ray study of the deformation mechanisms of non-woven polypropylene. Int. J. Solids Struct. 2016, 97, 200-208. [CrossRef]

27. Wang, Y.; Que, J.M.; Wang, C.; Li, C.H. Three-dimensional observations of meso-structural changes in bimsoil using X-ray computed tomography (CT) under triaxial compression. Constr. Building Mater. 2018, 190, 773-786. [CrossRef]

28. Patterson, B.M.; Cordes, N.L.; Henderson, K.; Mertens, J.C.E.; Clarke, A.J.; Hornberger, B.; Merkle, A.; Etchin, S.; Tkachuk, A.; Leibowitz, M.; et al. In situ laboratory-based transmission x-ray microscopy and tomography of material deformation at the nanoscale. Exp. Mech. 2016, 56, 1585-1597. [CrossRef]

29. Yuan, Z.-N.; Chen, H.; Li, J.-M.; Dai, B.; Zhang, W.-B. In-situ X-ray tomography observation of structure evolution in 1,3,5-triamino-2,4,6-trinitrobenzene based polymer bonded explosive (TATB-PBX) under thermo-mechanical loading. Materials 2018, 11, 732. [CrossRef] [PubMed]

30. Dai, B.; Zhang, W.-B.; Lan, L.-G.; Tian, Y. Experimental Study and DEM Simulation of Micro-Macro Behavior of TATB Granules During Compaction Using X-ray Tomography. Propellants Explos. Pyrotech. 2015, 40, 688-698. [CrossRef]

31. Yeager, J.D.; Manner, V.W.; Stull, J.A.; Walters, D.J.; Schmalzer, A.M.; Luscher, D.J.; Patterson, B.M. Importance of microstructural features in mechanical response of cast-cured HMX formulations. AIP Conf. Proc. 2018, 1979, 070033.

32. Liu, R.; Chen, P.W. Modeling ignition prediction of HMX-based polymer bonded explosives under low velocity impact. Mech. Mater. 2018, 124, 106-117. [CrossRef]

33. Hu, R.; Prakash, C.; Tomar, V.; Harr, M.; Gunduz, I.E.; Oskay, C. Experimentally-validated mesoscale modeling of the coupled mechanical-thermal response of AP-HTPB energetic material under dynamic loading. Int. J. Fract. 2017, 203, 277-298. [CrossRef]

34. Walters, D.J.; Luscher, D.J.; Yeager, J.D.; Patterson, B.M. Cohesive finite element modeling of the delamination of HTPB binder and HMX crystals under tensile loading. Int. J. Mech. Sci. 2018, 140, 151-162. [CrossRef]

35. Patterson, B.M.; Cordes, N.L.; Henderson, K.; Xiao, X.; Chawla, N. Data challenges of in situ X-ray tomography for materials discovery and characterization. In Materials Discovery and Design; Springer: Cham, Switzerland, 2018; pp. 129-165.

36. Rae, P.J.; Goldrein, H.T.; Palmer, S.J.P.; Field, J.E.; Lewis, A.L. Quasi-Static Studies of the Deformation and Failure of b-HMX Based Polymer Bonded Explosives. Proc. Math. Phys. Eng. Sci. 2002, 458, 743-762. [CrossRef]

37. Skidmore, C.B.; Phillips, D.S.; Son, S.F.; Asay, B.W. Characterization of HMX particles in PBX 9501. AIP Conf. Proc. 1998, 429, 579-582.

38. Yeager, J.D.; Ramos, K.J.; Singh, S.; Rutherford, M.E.; Majewski, J.; Hooks, D.E. Nanoindentation of explosive polymer composites to simulate deformation and failure. Mater. Sci. Technol. 2012, 28, 1147-1155. [CrossRef]

39. Peterson, P.D.; Idar, D.J. Microstructural Differences between Virgin and Recycled Lots of PBX 9502. Propellants Explos. Pyrotech. 2005, 30, 88-94. [CrossRef] 
40. Willey, T.M.; Lauderbach, L.; Gagliardi, F.; Cunningham, B.; Lorenz, K.T.; Lee, J.I.; van Buuren, T.; Call, R.; Landt, L.; Overturf, G. Comprehensive Characterization of Voids and Microstructure in TATB-based Explosives from $10 \mathrm{~nm}$ to $1 \mathrm{~cm}$ : Effects of Temperature Cycling and Compressive Creep. In Proceedings of the Fourteenth International Detonation Symposium, Coeur d'Alene, ID, USA, 11-16 April 2010.

41. Kinney, J.; Willey, T.; Overturf, G. On the nature of variations in density and composition within TATB-based plastic bonded explosives. In Proceedings of the Thirteenth International Detonation Symposium, Norfolk, VA, USA, 23-28 July 2006.

42. Bennett, K.C.; Zecevic, M.; Luscher, D.J.; Lebensohn, R.A. A thermo-elastoplastic self-consistent homogenization method for inter-granular plasticity with application to thermal ratcheting of TATB. Adv. Model. Simul. Eng. Sci. 2020, 7, 3. [CrossRef]

43. Luscher, D.; Yeager, J.; Clausen, B.; Vogel, S.; Duque, A.H.; Brown, D. Using neutron diffraction to investigate texture evolution during consolidation of deuterated triaminotrinitrobenzene (d-TATB) Explosive Powder. Crystals 2017, 7, 138. [CrossRef]

44. Yeager, J.D.; Watkins, E.B.; Duque, A.L.H.; Majewski, J. The thermal and microstructural effect of plasticizing HMX-Nitrocellulose composites. J. Energy Mater. 2018, 36, 13-28. [CrossRef]

45. Gustavsen, R.L.; Sheffield, S.A.; Alcon, R.R. Extended Run Distance Measurements Of Shock Initiation In Pbx 9502. AIP Conf. Proc. 2007, 955, 915-918.

46. Hoffman, D.M.; Willey, T.M.; Mitchell, A.R.; Depiero, S.C. Comparison of New and Legacy TATBs. J. Energy Mater. 2008, 26, 139-162. [CrossRef]

47. Bourne, N.K.; Milne, A.M. Shock to detonation transition in a plastic bonded explosive. J. Appl. Phys. 2004, 95, 2379-2385. [CrossRef]

48. Massoni, J.; Saurel, R.; Baudin, G.; Demol, G. A mechanistic model for shock initiation of solid explosives. Phys. Fluids 1999, 11, 710-736. [CrossRef]

49. Hamate, Y.; Horie, Y. Ignition and detonation of solid explosives: A micromechanical burn model. Shock Waves 2006, 16, 125-147. [CrossRef]

50. Burbelko, A.A.; Fraś, E.; Kapturkiewicz, W. About Kolmogorov's statistical theory of phase transformation. Mater. Sci. Eng. A 2005, 413, 429-434. [CrossRef]

51. Hayes, D.B.; Sandia National Labs. Shock Induced Hot-Spot Formation and Subsequent Decomposition in Granular, Porous HNS Explosive. In Shock Waves, Explosions, and Detonations; American Institute of Aeronautics and Astronautics: Reston, VA, USA, 1983; pp. 445-467.

52. Nichols, A.L., III; Tarver, C.M. A statistical hot spot reactive flow model for shock initiation and detonation of solid high explosives. In Proceedings of the Twelfth International Symposium on Detonation, San Diego, CA, USA, 11-16 August 2002; Office of Naval Research: Arlington, VA, USA, 2002.

53. Shaw, M.S.; Menikoff, R. A reactive burn model for shock initiation in a PBX: Scaling and separability based on the hot spot concept. In Proceedings of the 14th International Detonation Symposium, Los Alamos, NM, USA, 11 April 2010.

54. Hill, L. The Statistical Hot Spot Model: Dimensionality and the Effects of Time-Distributed Nucleation. In Proceedings of the 21st APS Topical Conference on Shock Waves in Condensed Matter, Portland, OR, USA, 16-21 June 2019.

(C) 2020 by the authors. Licensee MDPI, Basel, Switzerland. This article is an open access article distributed under the terms and conditions of the Creative Commons Attribution (CC BY) license (http://creativecommons.org/licenses/by/4.0/). 